\title{
Asphondylia fructicola, a new species of Cecidomyiidae (Diptera) associated with Solanum sp. (Solanaceae) from Brazil
}

\author{
Valéria Cid Maia ${ }^{1,2}$, Jean Carlos Santos $^{3} \&$ G. Wilson Fernandes ${ }^{3}$
}

1Museu Nacional, Depto. Entomologia, Quinta da Boa Vista, São Cristóvão 20940-040 Rio de Janeiro-RJ, Brazil. maiavcid@acd.ufrj.br
${ }^{2}$ Bolsista de Produtividade do CNPq
${ }^{3}$ Ecologia Evolutiva \& Biodiversidade/DBG, ICB/Universidade Federal de Minas Gerais. Caixa Postal 486, 30161-970 Belo Horizonte-MG, Brazil.

ABSTRACT. Asphondylia fructicola, a new species of Cecidomyiidae (Diptera) associated with Solanum sp. (Solanaceae) from Brazil. Asphondylia fructicola sp. nov. is described and illustrated on the basis of the larva, pupa, male, female, and gall. This species induces galls on fruits of Solanum sp. (Solanaceae) in Amazonia, Brazil.

KEYWORDS. Asphondylia; insect galls; taxonomy.

RESUMO. Asphondylia fructicola, uma nova espécie de Cecidomyiidae (Diptera) associada com Solanum sp. (Solanaceae) do Brasil. Asphondylia fructicola sp. nov. é descrita e ilustrada com base na larva, pupa, macho, fêmea e galha. Essa espécie induz galhas nos frutos de Solanum sp. (Solanaceae) na Amazônia, Brasil.

PALAVRAS-CHAVE. Asphondylia; galhas de insetos; taxonomia.

Recent studies have shown that the Amazonian tropical rain forest is rich in gall inducing insects (Julião et al. 2005), hence contradicting previous accounts on the galls in the region (Price et al. 1998). Otherwise, the knowledge on these species taxonomy, phylogeny, and host affiliations is poorly understood at present. In an attempt to begin and stimulate such studies we report on a new species of Asphondylia (Diptera: Cecidomyiidae) inducing galls on Solanum sp. (Solanaceae) in the largest tropical rain forest of the world, in the Brazilian Amazonia. The host plant was found in an reforested area, where it is relatively abundant and possibly an invader species.

The gall midge that induces galls on Solanum sp. belongs to Asphondylia Loew, 1850. This cosmopolitan genus includes 272 described species of gallers, of which most induce galls on flowers, fruits and less often on leaves and stems (Gagné 2004, Carneiro et al., personal communication). The genus is characterized by a needlelike ovipositor, two-toothed gonostylus, three-segmented palpi and presence of upper and generally lower horns on the pupal frons (Gagné 1994).

Asphondylia species have been recorded on 66 plant families, being most frequent on Asteraceae, Fabaceae and Chenopodiaceae (Gagné 2004). Ten species are associated with Solanaceae (Gagné 2004; Maia \& Fernandes 2005), six of them induce galls on Solanum species: Asphondylia beguni Mani, 1953 (distr.: India; host plant: Solanum melongena); A. obscura Kolesik, 2000 (distr.: Australia, host plant: Solanum physalifolium var. nitidibaccatum and Solanum chenopodioides); A. paucidentata Kolesik, 2000 (distr.: Australia, host plant: Solanum aviculare and S. linearifolium); A. solani Tavares, 1908 (distr.: Mozambique, host plant: Solanum sp.); A. sturtiana Kolesik, 2000 (distr.: Australia, host plant: Solanum sturtianum); and A. trabuti Marchal, 1896 (distr.: Algeria and Italy; host plant: Solanum tuberosum).

In the Neotropical region, only Asphondylia cestri Möhn, 1959 is associated with Solanaceae, but it induces galls on Cestrum nocturnum (Raat Ki Rani). Other Neotropical species belonging to distinct genera induce galls on Solanum spp., namely: Neolasioptera exigua Möhn, 1964 (distr.: El Salvador; host plant: S. umbellatum); Lasioptera kallstroemia Felt, 1935 (distr.: USA, Mexico, Guatemala, Nicaragua; host plant: Solanum spp.); and Prodiplosis longifilia (distr.: USA, Colombia, Ecuador, Peru; host plant: S. esculentum and $S$. tuberosum and others host plant family).

In Brazil, 14 species of Asphondylia have been recorded, none on Solanaceae.

\section{MATERIALAND METHODS}

Samples of galls were taken from plantations of a native species of Solanum L. (Solanaceae) in the Plateau Papagaio (01 ${ }^{\circ} 36^{\prime} 58.2$ S and 56 $24^{\prime} 14.4 \mathrm{~W}$ ) at the nursery of the Mineração Rio do Norte SA, Porto Trombetas, Pará State, Brazil in October 2005. We collected attacked fruits for rearing of immature and adults of the galling species, and parasitoids from 50 individuals of Solanum sp. The material was taken to the laboratory for rearing of insects. Sampled material was maintained at constant room temperature and humidity. Larvae were obtained by dissection of galls under a stereoscopic microscope. Pupal exuviae and adults were obtained by keeping galled fruits of Solanum sp. in plastic pots layered at the bottom with damp cotton and covered by fine nylon mesh. The pots were inspected daily for adult emergence. Immature stages and adults were fixed in $70 \%$ ethanol and then mounted 
on slides, following the methodology described by Gagné (1994). The specimens (including the types) are deposited in the Diptera collection of Museu Nacional, Rio de Janeiro (MNRJ). Morphological terminology for immature stages and adults follows Gagné (1994).

Additionally, we randomly selected 100 galled fruits of 50 plants in the field, which were placed in plastic bags and taken to the laboratory to record gall size (diameter) and weight. The parasitoid mortality factor (for details see Fernandes \& Price 1992) acting upon the galling larva, the abundance of larvae, pupae, adults and the presence of lodgers were also measured. The data were analyzed by basic statistical analyses (StatSoft 2001). The field and laboratory work were done by G.
W. Fernandes, J. C. Santos and collaborators while the taxonomy and descriptions of the new species were made by V.C. Maia.

\section{Asphondylia fructicola Maia, sp. nov.}

(Figs. 1-18)

Diagnosis. Adults: eye facets hexagonal, frontoclypeus with 14-22 setae in male and 16-20 in female; empodia well developed, as long as bend in claws or longer; male tergite 8 band-like with only two basal trichoid sensilla; female sternite 7 0.50-0.55 mm long, 1.66-1.76 as long as sternite 6; ovipositor: needle part 1.60-1.75 mm long and 3.0-3.3 as long as sternite 7 .

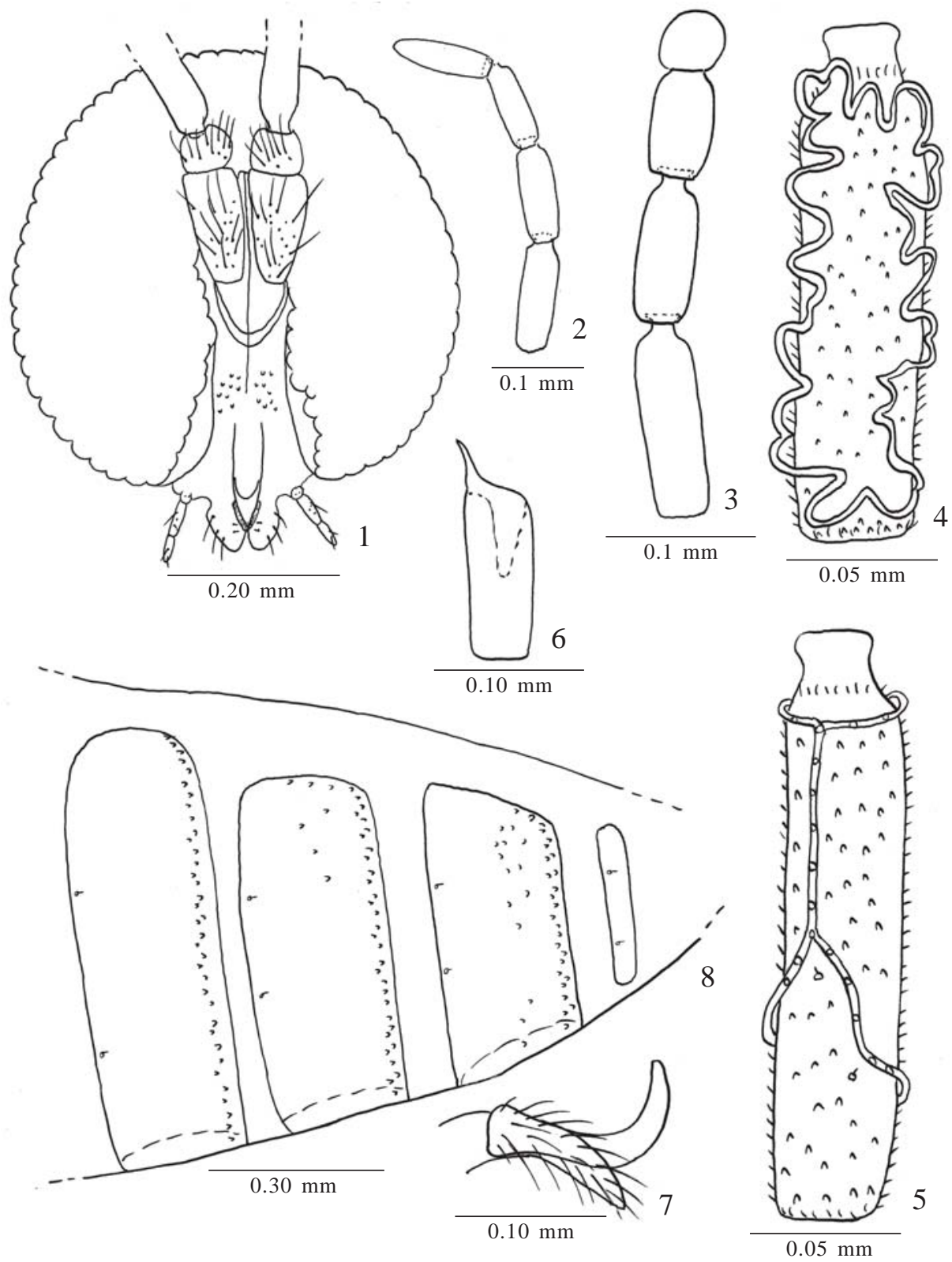

Figs. 1-8. Asphondylia fructicola, sp. nov.; 1, male head, frontal view; 2, male flagellomeres 9-12; 3, female flagellomeres 9-12; 4, male flagellomere 5; 5, female flagellomere 5; 6, male, midleg, first tarsomere; 7, female, midleg, tarsal claw and empodium, lateral view; 8, male abdominal segments $5-8$, dorsal view. 
Pupa: prothoracic spiracle setiform, curved, 0.16-0.17 mm long; antennal horn triangular with internal margin serrated, 0.30$0.33 \mathrm{~mm}$ long (from antennal base to apex); upper frontal horn simple, 0.05-0.06 mm long; lower frontal horn trilobed, 0.03$0.04 \mathrm{~mm}$ long; abdominal segments 2-8 with two transverse rows of crescent dorsal spines; segment 9 with scattered crescent dorsal spines. Larva: spatula 4-toothed; three setose lateral papillae on each side of spatula; four pairs of terminal papillae.

Adult. Body length: $3.1-3.8 \mathrm{~mm}$ in male ( $\mathrm{n}=9)$; $3.7-4.0 \mathrm{~mm}$ in female (from vertex to bilobed structure at posterior end of tergite 8) $(n=4)$. Head (Fig.1): eye facets hexagonal closely appressed. Antenna: scape obconical elongate, $0.11-0.16 \mathrm{~mm}$ long, 2.4-1.7 as long as wide and 2.1-2.75 as long as pedicel in male $(\mathrm{n}=11), 0.14-0.16 \mathrm{~mm}$ long, 2.1-2.6 as long as wide and 2.13.0 as long as pedicel in female $(\mathrm{n}=5)$; pedicel short globose 0.04-0.06 mm long and 0.81-1.0 as long as wide in male, 0.05$0.07 \mathrm{~mm}$ long and $0.88-0.89$ as long as wide in female; male flagellomeres 1-12 and female flagellomeres 1-11 cylindrical; female flagellomere 12 globose; flagellomere neck short and bare. Flagellomeres 1 and 2 not connate. Flagellomere 1: 0.19$0.28 \mathrm{~mm}$ long, 4.0-6.2 as long as wide and 1.46-1.83 as long as scape in male $(\mathrm{n}=11) ; 0.27-0.30 \mathrm{~mm}$ long, $7.5-8.3$ as long as wide and $1.75-2.0$ as long as scape in female $(\mathrm{n}=5)$; flagellomere 9: 0.14-0.15 mm long, 3.5-4.0 as long as wide and about as long as flagellomere 10 in male $(\mathrm{n}=11), 0.12-0.13 \mathrm{~mm}$ long, 3.27-3.69 as long as wide and 1.18-1.30 as long as flagellomere 10 in female ( $\mathrm{n}=5$ ); flagellomere 10: 0.14-0.15 mm long, 3.5-4.0 and as long as wide and about as long as flagellomere 11 in male $(\mathrm{n}=11)$; 010-0.11 mm long, 2.3-2.8 as long as wide in female and $1.57-1.67$ as long as flagellomere $11(\mathrm{n}=11)$; flagellomere 11 : $0.13-0.14 \mathrm{~mm}$ long, 3.7-4.0 as long as wide and about as long as flagellomere 12 in male ( $\mathrm{n}=11), 0.06-0.07 \mathrm{~mm}$ long, $1.2-2.0$ as long as wide and 1.5-1.75 as long as flagellomere 12 in female $(\mathrm{n}=5)$; flagellomere 12: $0.12-0.13 \mathrm{~mm}$ long and 3.0-4.1 as long as wide in male $(\mathrm{n}=11) ; 0.04 \mathrm{~mm}$ long and $0.9-1.1$ as long as wide in female $(n=5)$. Proportions of last four male and female flagellomeres as in Figs.2-3, respectively. Circumfila anastomosing in male (Fig.4) and as two interconnected rings in female (Fig.5). Frontoclypeus with 14-22 setae in male and 16-20 in female. Labrum long-attenuate. Hypopharynx of the same shape of labrum, with long anteriorly directed lateral setulae. Labella elongate-convex, each with some lateral setae and two pairs of short mesal setae. Palpus with three setose segments: segment one globose, $0.020-0.025 \mathrm{~mm}$ long and $1.0-$ 1.55 as long as wide in male $(\mathrm{n}=8), 0.020-0.030 \mathrm{~mm}$ long, 0.83 1.85 as long as wide; segment 2 claviform, $0.025-0.04 \mathrm{~mm}$ long, $1.72-2.25$ as long as wide and 1.5-2.0 as long as segment one in male ( $\mathrm{n}=6), 0.04-0.05 \mathrm{~mm}$ long, 1.76-2.27 as long as wide and $1.5-2.25$ as long as segment one in female $(\mathrm{n}=5)$; segment $3 \mathrm{~mm}$ claviform, 0.04-0.055 mm long, 2.4-4.4 as long as wide and 1.251.80 as long as segment 2 in male $(\mathrm{n}=8), 0.05-0.075 \mathrm{~mm}$ long, 2.6-4.4 as long as wide and 1.20-1.87 as long as segment one in female $(\mathrm{n}=5)$.

Thorax: Anepimeron setose, other pleural sclerites asetose.

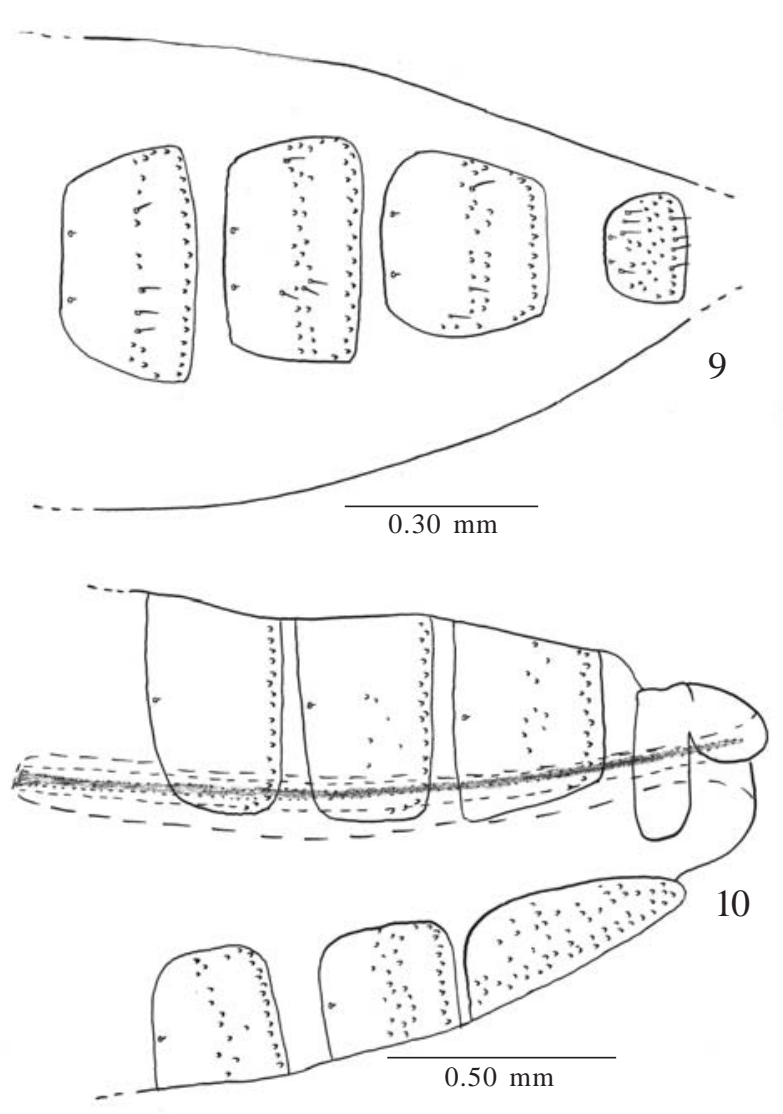

Figs. 9-10. Asphondylia fructicola, sp. nov.; 9, male abdominal segments 5-8, ventral view; 10 , female abdominal segment 5 to end, lateral view.

Wing length (from arculus to apex): 2.0-2.4 $\mathrm{mm}$ in male ( $\mathrm{n}=5$ ), $2.7-2.85 \mathrm{~mm}$ in female $(\mathrm{n}=4)$. First tarsomere with apical projection $0.03 \mathrm{~mm}$ long in both sexes, thinner in male $(\mathrm{n}=10)$ (Fig. 6).Tarsal claws simple, robust, curved beyond midlength; empodia well developed, as long as bend in claws or longer (Fig.7).

Abdomen: Male (Figs.8-9): tergites 1-7 rectangular with complete row of posterior setae, several lateral setae, two basal trichoid sensilla and elsewhere with scattered scales. Tergite 8 band-like with only two basal trichoid sensilla as vestiture. Sternites 2-7 rectangular with setae more abundant at midlength, complete row of posterior setae, several lateral setae, two basal trichoid sensilla and elsewhere with scattered scales. Sternite 8 ovoid with several scattered setae more concentrated caudally and two basal trichoid sensilla. Female (Fig.10): tergites 1-8 as tergite 1-7 in male; sternites 2-6 as sternites 2-6 in male. Sternite 7 ovoid, $0.50-0.55 \mathrm{~mm}$ long, 1.66 1.76 as long as sternite 6 , with scattered setae and two basal trichoid sensilla. Sternite 8 not sclerotized. Male terminalia (Fig.11): gonocoxites wide and setose, 0.13-0.14 $\mathrm{mm}$ long, 0.08$0.095 \mathrm{~mm}$ wide and $1.47-1.68$ as long as wide $(\mathrm{n}=3)$, with small apical lobe; gonostylus short, ovoid, and setose, 0.065-0.07 $\mathrm{mm}$ long, $0.045-0.05 \mathrm{~mm}$ wide, $1.3-1.55$ as long as wide $(\mathrm{n}=2)$; cercus reniform or triangular, completely separate and setose, 


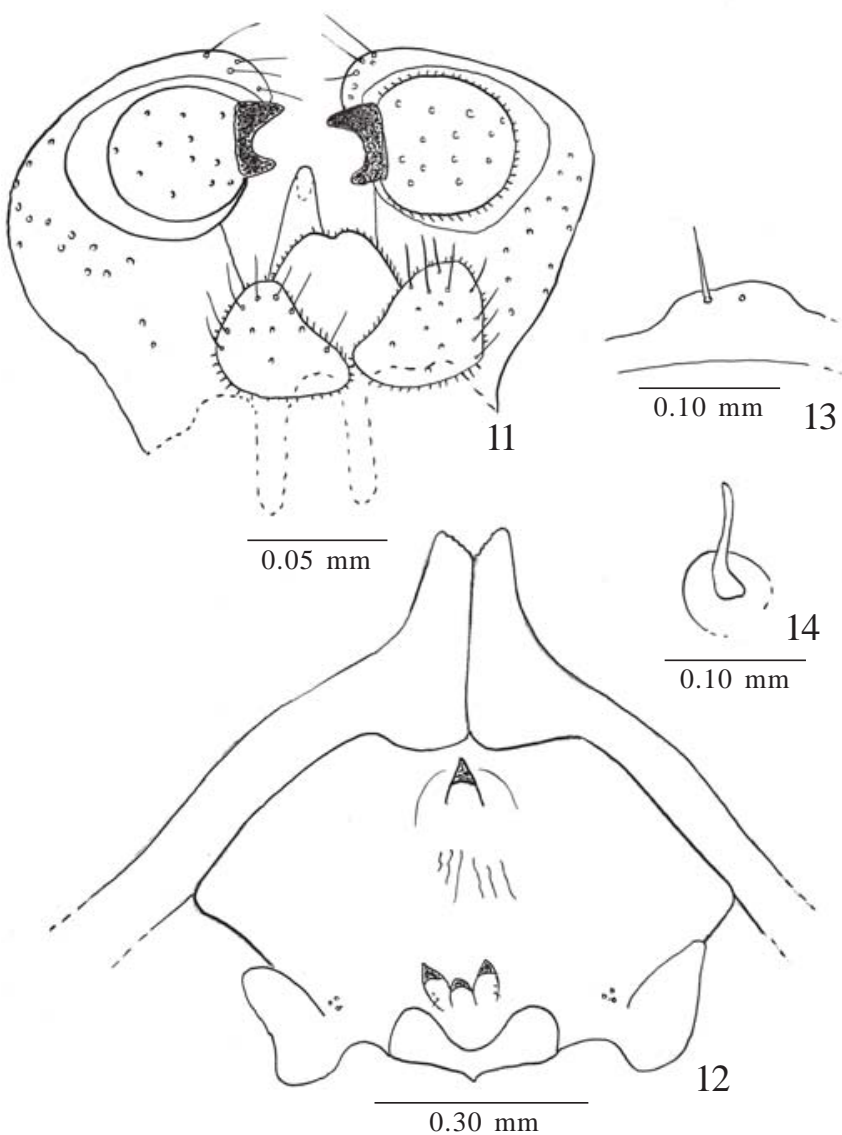

Figs. 11-14. Asphondylia fructicola, sp. nov.; 11, male terminalia, dorsal view; 12, pupa, head, frontal view; 13, pupa, cephalic seta, dorsal view; 14, pupa. prothoracic spiracle.

0.045-0.05 mm long $(\mathrm{n}=3)$; hypoproct bilobed and setose; parameres absent; aedeagus triangular, tapering gradually towards apex and pointed apically. Ovipositor: needle part 1.60-1.75 mm long $(\mathrm{n}=4)$ and 3.0-3.3 as long as sternite $7(\mathrm{n}=4)$.

Pupa. Color: brownish. Length: 3.1-3.9 mm (n=6). Head (Fig.12): antennal horn triangular with internal margin serrated, and $0.30-0.33 \mathrm{~mm}$ long (from antennal base to apex) $(\mathrm{n}=5)$; cephalic setae 0.055-0.06 mm long (Fig.13) ( $\mathrm{n}=6$ ); upper frontal horn simple, 0.05-0.06 mm long $(\mathrm{n}=5)$; lower frontal horn trilobed, 0.03-0.04 mm long ( $\mathrm{n}=4)$; two pairs of lower facial papillae: one pair setose, seta $0.02 \mathrm{~mm}$ long $(\mathrm{n}=4)$, the other asetose; three pairs of lateral facial papillae: one pair setose, seta $0.01 \mathrm{~mm}$ long $(n=4)$, the others without setae. Upper cephalic margin thickened laterally. Thorax: prothoracic spiracle setiform, curved, 0.16-0.17 mm long ( $\mathrm{n}=4)$ (Fig. 14). Abdomen (Fig.15): segments 2-8 with two transverse rows of crescent dorsal spines.Segment 9 with scattered crescent dorsal spines.

Larva. Body elongate and cylindrical. Length: 3.3-3.7 mm $(n=4)$. Integument rough. Spatula with four well developed teeth, the outer ones longer than the inner; surrounding area pigmented; sternal papillae setose (setae $0.015 \mathrm{~mm}$ long, $\mathrm{n}=4$ ), three setose lateral papillae on each side of spatula, one papillae longer than the others, the longest $0.008 \mathrm{~mm}$ long, the others $0.005 \mathrm{~mm}$ long ( $\mathrm{n}=3$ ) (Fig. 16). Terminal segment short, convex, with four pairs of terminal papillae, being to setose and the others bare (Fig. 17).

Gall (Fig. 18). Galls develop on fruits of Solanum sp. Galled fruits are conspicuous due to their size and distinct ruptures on the fruit cortex. The galls are green, covered with short, whitish trichomes, and multiple chambered. Several larvae are found inside the gall, each one in a separate chamber. At the beginning of gall formation, it is similar in shape with young fruits. As the gall matures, it becomes enlarged and globose. Many cracks appear on the gall walls in which eventually inquiline arthropods such as cockroaches, ants, homopterous, and coleopterans live. The A. fructicola fruit galls studied had a diameter of $20.84 \pm 4.67 \mathrm{~mm}(\bar{x} \pm \mathrm{SD} ;$ min. $=10.00$ and $\max .=32.60$, $\mathrm{n}=100)$ and an average weight of $3.09 \pm 1.77 \mathrm{~g}(\bar{x} \pm \mathrm{SD} ; \mathrm{min} .=0.38$ and max. $=8.79, \mathrm{n}=100$ ). The proportion of individuals found at the same time during the study in the fruit galls was as follow: larva $40.27 \%(n=60)$; pupa $32.89 \%(n=49)$; adult $1.34 \%(n=2)$ and parasitized larvae $25.50 \%(\mathrm{n}=38)$. Other studies of Asphondylia species inducing galls in fruit have been done, for instance, A. aucubae Yukawa et Ohsaki on a dioecious shrub Aucuba japonica Thunberg (Aucubaceae) (Imai \& Ohsaki 2004).
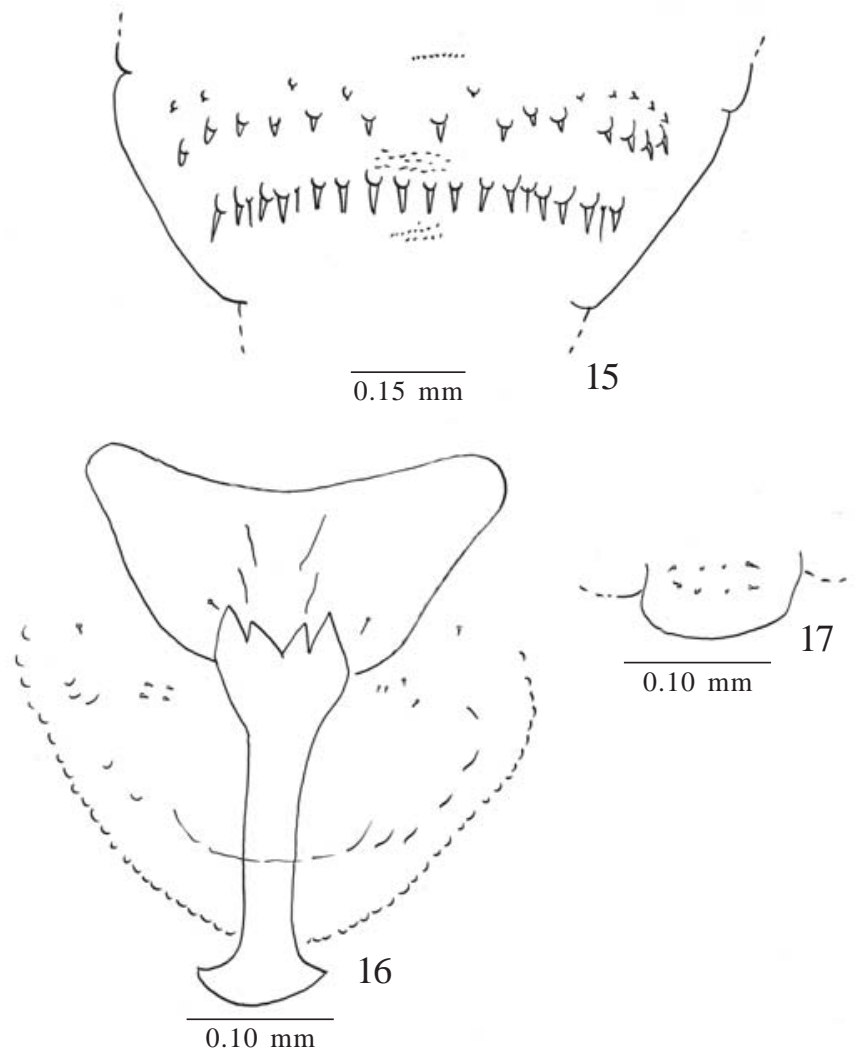

Figs. 15-17. Asphondylia fructicola, sp. nov.; 15, pupa, abdominal segment 8 , dorsal view; 16 , larva, spatula and associated papillae, ventral view; 17, Larva, terminal segment, dorsal view. 


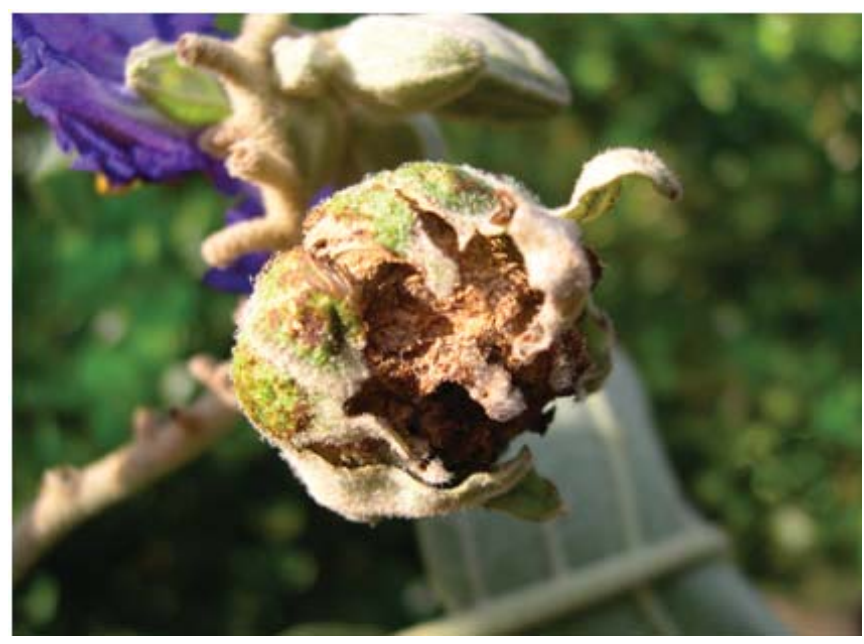

Fig. 18. Gall induced by Asphondylia fructicola, sp. nov., general aspect.

Material Examined. Holotype male, fruit galls on Solanum sp., BRAZIL. Pará, Porto Trombetas, X.2005, G. W. Fernandes col.. MNRJ. Paratypes: same data as holotype, 10 males, 5 females, 8 pupal exuviae, and 4 larvae.

Etymology. The name fructicola refers to the organ plant where the gall midge larva lives.

Remarks. Asphondylia fructicola is unique in having the combination of the following characters: empodia well developed, as long as bend in claws or longer; male tergite 8 band-like with only two basal trichoid sensilla; female sternite 7 1.66-1.76 as long as sternite 6; ovipositor: needle part 1.60$1.75 \mathrm{~mm}$ long and 3.0-3.3 as long as sternite 7. prothoracic spiracle $0.16-0.17 \mathrm{~mm}$ long; antennal horn triangular with internal margin serrated, $0.30-0.33 \mathrm{~mm}$ long; upper frontal horn simple, 0.05-0.06 mm long; lower frontal horn trilobed, 0.03$0.04 \mathrm{~mm}$ long; abdominal segments 2-8 with two transverse rows of crescent dorsal spines; segment 9 with scattered crescent dorsal spines; spatula 4-toothed; three setose lateral papillae on each side of spatula; four pairs of terminal papillae.

It differs from A. cestri, the only other Neotropical species of Asphondylia associated with Solanaceae by: 1) body length: 2.4-2.5mm in male and 2.7-2.8mm in female of A. cestri, 3.1-3.8 $\mathrm{mm}$ in male and $3.7-4.0 \mathrm{~mm}$ in female of A. fructicola; 2) proportions of the last three female flagellomeres: flagellomere 10: $0.08 \mathrm{~mm}$ long in A. cestri and $0.10-0.11 \mathrm{~mm}$ long in $A$. fructicola; flagellomere $11: 0,058 \mathrm{~mm}$ long in A. cestri and 0.06$0.07 \mathrm{~mm}$ long in A. fructicola; and flagellomere 12: $0.01 \mathrm{~mm}$ long in A. cestri and $0.04 \mathrm{~mm}$ long in A. fructicola; 3) empodium longer in A. fructicola than in A. cestri (see Figure 86 of Möhn 1959); and 4) spatula with teeth more pointed in A. fructicola than in A. cestri (see Figure 87 of Möhn 1959), the two lateral teeth are conspicuously longer than the mesal ones only in the new species.

Acknowledgments. We thank D. Braga for field help. This study was supported by the Mineração Rio do Norte, Planta Tecnologia Ambiental, CNPq (30 4851/2004-3), FAPERJ (Fundação de Amparo à Pesquisa do Estado do Rio de Janeiro, E-26/171.290/2006) and CNPq (Conselho Nacional de Desenvolvimento Científico e Tecnológico, Proc. 472084/2007-0 e 301197/2007-5). We also thank the administration of the Flona Saracá-Taquera - IBAMA National Forest for logistical support.

\section{REFERENCES}

Fernandes, G. W. \& P. W. Price. 1992. The adaptive significance of insect gall distribution: survivorship of species in xeric and mesic habitats. Oecologia 90: 14-20.

Gagné, R. J. 1994. The Gall Midges of the Neotropical Region. Cornell University Pres, Ithaca, xi +356 p., 4 pls.

Gagné, R. J. 2004. A catalog of the Cecidomyiidae (Diptera) of the world. Memoirs of the Entomological Society of Washington 25: 408 p.

Imai, K. \& N. Ohsaki. 2004. Oviposition site of and gall formation by the fruit gall midge Asphondylia aucubae (Diptera: Cecidomyiidae) in relation to internal fruit structure. Entomological Science 7: $133-137$.

Julião, G. R.; E. M. Venticinque \& G. W. Fernandes. 2005. Richness and abundance of gall-forming insects in the Mamirauá Varzea, a flooded Amazonian forest. Uakari 1: 39-42.

Maia, V. C. \& G. W. Fernandes. 2005. Two new species of Asphondyliini (Diptera: Cecidomyiidae) associated with Bauhinia brevipes (Fabaceae) in Brazil. Zootaxa 1091: 27-40.

Möhn, E. 1959. Gallmücken (Diptera, Itonididae) aus El Salvador. 1. Teil. Senckenbergiana Biologica 40: 297-368.

Price, P. W.; G. W. Fernandes; A. C. F. Lara; J. Brawn; D. Gerling; H. Barrios; M. Wright; S. P. Ribeiro \& N. Rothcliff. 1998. Global patterns in local number of insect galling species. Journal of Biogeography 25: 581-592.

StatSoft Inc. 2001. STATISTICA 6.0 for Windows [Computer program manual]. StatSoft, Tulsa, Okla. USA. http://www.statsoft.com

Received 07/05/2008; accepted 18/11/2008 